\title{
Atenção à Saúde do bebê na Rede Cegonha: um diálogo com a teoria de Winnicott sobre as especificidades do desenvolvimento emocional
}

\author{
I ${ }^{1}$ Georgius Cardoso Esswein, ${ }^{2}$ Lívia Padilha de Teixeira, \\ ${ }^{3}$ Rita de Cássia Sobreira Lopes, ${ }^{4}$ César Augusto Piccinini I
}

Resumo: O Ministério da Saúde instituiu, em 2011, a Rede Cegonha através da Portaria ${ }^{\circ} 1.459$, visando assegurar um atendimento integral e integrado, da gestação até os 24 meses de vida do bebê. A partir desse importante avanço, este artigo tem como objetivo promover uma análise crítica da Portaria da Rede Cegonha a partir de um diálogo com a teoria do amadurecimento pessoal de Winnicott. Os resultados são apresentados a partir de quatro eixos norteadores: Características integradoras do cuidado, em que discutimos características da Rede Cegonha favorecedoras de um cuidado integrador; Cuidar do cuidador, em que salientamos a possibilidade de essa rede colaborar com a sustentação da dupla mãe-bebê; Especificidades do cuidado à saúde materno-infantil, em que atentamos às especificidades do processo de desenvolvimento emocional inicial; e Ética do cuidado, em que destacamos a necessidade de uma postura ética implicada no cuidado. Este artigo indicou as potencialidades e fragilidades da Rede Cegonha, trazendo novas proposiçóes, que visem aprimorar a atenção à saúde materno-infantil, sobretudo nos dois primeiros anos de vida. Por fim, salientamos que apesar de a portaria não garantir como o cuidado é operacionalizado, reiteramos o importante potencial que a Rede Cegonha possui para um cuidado integrador na atenção à saúde materno-infantil.

> Palavras-chave: cuidado à saúde materno-infantil; Sistema Único de Saúde; Psicanálise; desenvolvimento infantil.
1 Programa de Pós-Graduação em Psicologia, Universidade Federal do Rio Grande do Sul. Porto Alegre-RS, Brasil (georgius. esswein@gmail.com). ORCID: 0000-0002-6757-1954

2 Programa de Pós-Graduação em Psicologia, Universidade Federal do Rio Grande do Sul. Porto Alegre-RS, Brasil (liviapteixeira@ gmail.com).

ORCID: 0000-0003-3891-8688

3 Programa de Pós-Graduação em Psicologia, Universidade Federal do Rio Grande do Sul. Porto Alegre-RS, Brasil (sobreiralopes@ portoweb.com).

ORCID: 0000-0002-6433-1648

${ }^{4}$ Programa de Pós-Graduação em Psicologia, Universidade Federal do Rio Grande do Sul. Porto Alegre-RS, Brasil (piccinini@ portoweb.com.br).

ORCID: 0000-0002-4313-3247

Recebido em: 02/10/2019 Aprovado em: 03/03/2020 Revisado em: 09/07/2021 


\section{Introdução}

Diversos estudos da área da saúde vêm demonstrando a importância de políticas voltadas aos primeiros anos de vida da criança e, em particular, ao cuidado à relação mãe-bebê. Tais ações de saúde têm sido consideradas como fatores de proteção, com impacto em diversos aspectos e etapas do desenvolvimento. No âmbito nacional, Victora (2016) reitera tais evidências, salientando a importância dos primeiros mil dias do bebê - período que inclui a gestação, acrescido dos primeiros dois anos de vida -, pois se trata de um período do desenvolvimento da criança fundamental para a sua saúde. Tal concepção tem sido relevante na legislação brasileira voltada à saúde materno-infantil, sendo utilizada para fundamentar proposiçóes específicas para essa etapa da vida.

Neste contexto que envolve os anos iniciais de vida da criança, o Brasil tem um considerável percurso de investimento em políticas e programas voltados à saúde e à especificidade dessa população. Recentemente, a Portaria ${ }^{\circ} 1.459$ instituiu a Rede Cegonha (BRASIL, 2011), considerado o programa mais completo de atenção voltada à saúde materno-infantil (MARQUES, 2016). Trata-se de uma rede que visa produzir uma nova organização do cuidado (PASCHE et al., 2014), assegurando o direito ao planejamento reprodutivo, atenção e acompanhamento da gestante no pré-natal, parto e puerpério, bem como ao nascimento e crescimento saudável do bebê (BRASIL, 2011).

Atualmente, diversas são as áreas de conhecimento que se ocupam desse processo de desenvolvimento da criança, em particular, a medicina, fonoaudiologia, psicologia, sociologia, serviço social, entre outros. No campo da psicologia, e mais especificamente da psicanálise, o pediatra e psicanalista D. W. Winnicott destaca-se com importantes contribuiçóes para compreender o desenvolvimento emocional e a natureza humana. Para ele, a natureza humana trata-se de uma tendência inata à integração e ao amadurecimento.

$\mathrm{O}$ autor resguarda em sua teoria um espaço muito importante para as primeiras experiências do bebê com o ambiente, desde a sua gestação. A partir de uma ampla experiência clínica de pediatria com bebês e com a prática da psicanálise, propóe o amadurecimento emocional como um processo a ser conquistado pelo ser humano, desde que facilitado pelo ambiente. Nesse sentido, sua teoria amplia o conceito psicanalítico de desenvolvimento, introduzindo a relação do indivíduo 
com o ambiente no processo de amadurecimento pessoal (CARON; LOPES, 2014; FULGENCIO, 2011; WINNICOTT, 2007a; 1990). Além disso, Winnicott ilumina o estreito vínculo entre saúde e desenvolvimento em sua teoria, a qual se torna fecunda para articular-se com açôes em saúde pública, sobretudo na área materno-infantil.

Este artigo tem como objetivo promover uma análise crítica da Portaria da Rede Cegonha (BRASIL, 2011) a partir de um diálogo com a teoria do amadurecimento pessoal de Winnicott. A análise crítica tem como foco identificar potencialidades, fragilidades e/ou desafios da Rede Cegonha, visando produzir contribuiçôes teóricas para o campo da saúde pública, principalmente em seu âmbito estratégico. Para tal discussão, foi analisado o documento da Portaria que estabelece a Rede Cegonha, a partir de seus objetivos, princípios, diretrizes e componentes.

Para tanto, o artigo está dividido em quatro tópicos: no primeiro, apresentase um histórico da atenção à saúde materno-infantil no SUS, com uma breve contextualização sobre a construção de algumas das principais políticas públicas brasileiras voltadas a esse contexto; no segundo, apresenta-se a Rede Cegonha, enquanto programa organizador de atenção à saúde materno-infantil, contemplando sua construção enquanto Rede de Atenção à Saúde, e sua estrutura com objetivos, princípios e diretrizes; no terceiro, descrevem-se alguns dos principais pontos da teoria do amadurecimento pessoal de Winnicott e saúde utilizada nesta análise crítica; e, por fim, na quarta seção, são apresentados pontos de discussão e diálogo entre a teoria de Winnicott e o que é instituído na portaria da Rede Cegonha.

\section{Histórico de atenção à saúde materno-infantil no SUS}

A saúde pública do Brasil é amparada pelo Sistema Único de Saúde (SUS), instituído a partir da Constituição Federal de 1988 (BRASIL, 1990), considerado um dos maiores sistemas universais de saúde do mundo (GIOVANELLA et al., 2018). O SUS é considerado a maior política de inclusão social da história do Brasil (MENDES, 2013), uma vez que assegura o acesso à saúde enquanto um direito de todo cidadão brasileiro. Desde sua implantação, o SUS vem vivenciando alteraçôes e inovaçôes em sua operacionalização, desde o nível de gestão até as práticas desenvolvidas pelos profissionais (PERREAULT et al., 2016).

No âmbito de políticas e programas voltados à saúde materno-infantil, o Brasil já tem uma trajetória, antes mesmo da consolidação do SUS. O primeiro programa 
nacional a atentar integralmente para as necessidades clínico-ginecológicas, de prénatal, parto e puerpério foi instituído em 1984. Trata-se do Programa de Assistência Integral à Saúde da Mulher - PAISM (BRASIL, 1984), sendo também o primeiro programa dedicado ao planejamento familiar. É interessante notar que o PAISM é reconhecido como um marco histórico em termos de avanços no cuidado integral à saúde da mulher, família e criança. Esse programa buscou superar a fragmentação da assistência, as quais limitavam a atenção à saúde da mulher apenas ao ciclo gravídico (CASSIANO et al., 2014).

Apesar de o PAISM ter proposto um deslocamento de olhar sobre a saúde da mulher, a sua implementação em diferentes partes do Brasil se deu de forma bastante heterogênea (SERRUYA; CECATTI; LAGO, 2004). Ainda, apesar da redução da taxa de mortalidade materna, tais índices ainda permaneciam altos, se comparados com outros países (CASSIANO et al., 2014).

Considerando também tais desafios, mais recentemente o Ministério da Saúde lançou no ano de 2000 o Programa de Humanização no Pré-Natal - PHPN (BRASIL, 2000) buscando novas perspectivas de cuidado para gestantes e recémnascidos. Trata-se de um programa oriundo da preocupação em prestar uma atenção à saúde para além da redução da morbimortalidade materno-infantil, aumentando a cobertura, o acesso, além de promover a organização e regulamentação no âmbito do SUS. A PHPN garante que diversas práticas sejam pautadas em direitos, como a máe ter a presença de um acompanhante durante o período de pré-parto, parto e puerpério; poder se vincular a uma maternidade de referência; e ter alojamento conjunto, de maneira que o bebê passe a estar em contato com a mãe o tempo todo após o nascimento, e não apenas no período de amamentação (CASSIANO et al., 2014). No entanto, Silva, Cecatti e Serruya (2005) relatam que avaliações posteriores indicaram que, apesar de uma boa cobertura, alguns problemas necessitavam ser revistos, tais como o não cumprimento de normas do programa, a captação das gestantes e o número de consultas e exames, e atenção desarticulada.

Outra política importante para a saúde materno-infantil, abrangendo um período mais extenso que a perinatalidade, foi a Estratégia Brasileirinhas e Brasileirinhos Saudáveis - EBBS (BRASIL, 2009). Conforme Penello et al. (2011), esse programa buscou atender às recomendaçôes da Organização Mundial da Saúde (OMS) de priorizar os cuidados para a primeira infância, no que se refere às políticas públicas para minimizar as desigualdades. A EBBS tem como bases conceituais autores como 
Bowlby e Winnicott, importantes teóricos da área do desenvolvimento humano. Nessa articulação, consideram que a integração do ser humano na sociedade é antecedida por experiências anteriores, relacionadas às primeiras experiências do bebê com sua mãe. Assim, insere-se no contexto de políticas públicas o conceito de ambiente facilitador, referindo-se a um contexto propício que favorece a saúde e desenvolvimento do bebê e de sua mãe.

Desta forma, a Estratégia Brasileirinhas e Brasileirinhos se propóe a fornecer elementos para a implementação de uma política que se comprometesse com a atenção integral à primeira infância, fomentando o diálogo entre diferentes componentes da rede, tais como a Educação, Assistência Social, Justiça, Direitos Humanos, entre outros. Como descrito por Pitombo, Maia e Rosario (2014), essa estratégia desdobrouse em importantes contribuiçóes para a formulação da Política Nacional de Atenção Integral à Saúde da Criança - PNAISC (BRASIL 2015), posteriormente abordada.

No entanto, apesar dos esforços na criação dessas políticas, a OMS e a Organização Pan-Americana de Saúde identificaram que, nas Américas, a organização dos sistemas de saúde ainda se encontrava segmentada, com dificuldade de acesso e pouca satisfação dos usuários quanto aos serviços prestados (DI GIOVANNI, 2013). Assim, como uma forma de superar a fragmentação e aperfeiçoar a atenção à saúde, foram instituídas as Redes de Atenção à Saúde - RAS (BRASIL, 2010). Trata-se de arranjos organizativos de açôes e serviços de saúde organizados por temas de atuação. Essas redes possuem diferentes níveis de atenção e tecnologias, integradas a partir de uma estrutura de apoio técnico, logístico e de gestão (BRASIL, 2010; BRASIL, 2014; CASSIANO et al., 2014; PASCHE et al., 2014). Cada rede é composta por uma ampla gama de açôes de cunho preventivo e curativo, e buscam proporcionar um espaço de integração dos serviços, continuidade das açôes de cuidado, bem como uma organização vertical dos diferentes níveis de atenção. Assim, dentre as diferentes redes temáticas de atenção, foi estabelecida a Rede Cegonha, detalhada a seguir.

\section{Rede Cegonha e a atenção à saúde materno-infantil}

A Rede Cegonha configura-se enquanto uma rede de atenção à saúde focada no processo de desenvolvimento do bebê desde a gestação até os dois anos de vida, englobando também a atenção à saúde da mulher durante a gestação, o parto e o puerpério (BRASIL, 2011). A criação dessa rede surgiu no intuito de atender à saúde 
integral do bebê, com suas especificidades, dentre as quais a necessidade de cuidados contínuos e integrados tanto ao bebê quanto ao cuidador (BRASIL, 2014).

Essa estratégia busca superar a fragmentação da atenção à saúde das mulheres e bebês, por meio da qualificação das açôes e serviços de saúde, e combate à violência obstétrica, à medicalização e à mercantilização do parto (BRASIL, 2014; MARQUES, 2016). Assim, a Rede Cegonha visa favorecer a integração da informação e da atenção entre os diferentes serviços e níveis do SUS que estáo ou poderão estar envolvidos na vida da criança e da mulher.

Com a finalidade de humanização e integração do cuidado, a Rede Cegonha organiza-se a partir dos seguintes objetivos: fomentar a implementação de novo modelo de atenção à saúde da mulher e à saúde da criança; organizar a Rede de Atenção à Saúde Materna e Infantil para que esta garanta acesso, acolhimento e resolutividade; e reduzir a mortalidade materna e infantil com ênfase no componente neonatal (BRASIL, 2011).

A fim de orientar as ações realizadas, a Rede Cegonha foi estruturada com os seguintes princípios:

I - o respeito, a proteção e a organizaçáo dos direitos humanos; II - o respeito à diversidade
cultural, étnica e racial; III - a promoçáo da equidade; IV - o enfoque de gênero; V - a
garantia dos direitos sexuais e dos direitos reprodutivos de mulheres, homens, jovens e
adolescentes; VI - a participaçáo e a mobilizaçáo social; e VII - a compatibilizaçáo com
as atividades das redes de atençáo à saúde materna e infantil em desenvolvimento nos
Estados (BRASIL, 2011, p. 2).

Com isso, para sua organização e operacionalização, a Rede Cegonha é estruturada em quatro componentes, que estabelecem a garantia de um conjunto de rotinas e práticas de cuidados em saúde (BRASIL, 2011), sendo eles:

o Pré-Natal: realização do pré-natal na Unidade Básica de Saúde, com atenção às intercorrências e exames necessários, além do acesso em tempo ao pré-natal de risco; vinculação da gestante ao local de parto; qualificação do sistema de informações; estratégias e programas voltados à saúde sexual e reprodutiva.

o Parto e Nascimento: suficiência de leitos obstétricos e neonatais; práticas de atenção à saúde baseadas em evidências; garantia de acompanhante durante todo o processo do parto e pós-parto imediato; acolhimento e classificação de risco; estímulo à implementação de equipes horizontais de cuidado; e estímulo à participação dos usuários em cogestão. 
o Puerpério e Atenção Integral à Saúde da Criança: promoção do aleitamento materno e alimentação complementar; acompanhamento da puérpera e da criança na Atenção Básica, com busca ativa em contextos vulneráveis; estratégias voltadas à saúde sexual e reprodutiva; e tratamento de DST e hepatite.

o Sistema Logistico: transporte seguro para gestantes, puérperas e recém-nascidos de alto risco para acesso aos serviços de saúde; plano de vinculação da gestante ao local do parto; e regulação de leitos obstétricos e neonatais.

Sobre a operacionalização da Rede Cegonha, estipulou-se que a mesma deveria ser implementada de forma gradativa, atenta às especificidades de cada população e região. Sua atuação, mais especificamente, se dá pela integração dos serviços de saúde da atenção primária e especializada do SUS (MARQUES, 2016). Mais recentemente, em 2015, o Ministério da Saúde instituiu uma política para a infância que reestrutura a forma como as redes temáticas operacionalizam esses cuidados. Trata-se da Política Nacional de Atenção Integral à Saúde da Criança - PNAISC (BRASIL, 2015), que propõe uma estratégia integrada de atenção à saúde da criança da gestação até os nove anos de vida.

A PNAISC tem como objetivo promover e proteger a saúde da criança e o aleitamento materno através de um cuidado integral durante todo o período da infância, com especial atenção à primeira infância e populaçôes vulneráveis, visando à redução da mobimortalidade e a garantia de um ambiente facilitador, com condiçôes dignas para o desenvolvimento. Sua estrutura está organizada a partir de diferentes eixos, e é articulada principalmente por meio de açôes e serviços de saúde das redes temáticas, sobretudo a rede voltada à saúde materno-infantil, a Rede Cegonha. Dessa forma, observa-se que o atual panorama de atenção à saúde materno-infantil é decorrente de uma ampla discussão e de um histórico de políticas voltadas para esta população.

Assim como a PNAISC, a Rede Cegonha integra diferentes açóes e direitos já estabelecidos em programas e estratégias anteriores, bem como estrutura uma nova proposta de cuidado, instituindo-se como uma contraposição a um modelo fragmentado. No entanto, particularmente a Rede Cegonha caracteriza-se como a rede temática específica do cuidado materno-infantil. Essa especificidade atesta o reconhecimento da demanda de um atendimento planejado, integrado, organizado e que contemple as especificidades da dupla mãe-bebê, amplamente ressaltado por 
diversos teóricos do desenvolvimento infantil, entre eles o pediatra e psicanalista Winnicott $(2005 ; 2007$; 1999a; 2000), como será destacado a seguir.

\section{Saúde e desenvolvimento emocional do bebê na teoria de Winnicott}

Por sua experiência como pediatra, Winnicott compreendeu desde muito cedo que saúde é muito mais do que o bom funcionamento dos órgãos, e que separar o físico e o psíquico é um procedimento artificial (DIAS, 2003). Em sua concepção teórica, a saúde tem estreita ligação com o amadurecimento, sendo essencialmente pensada como maturidade apropriada à idade. Reconhece, também, que estar doente, muitas vezes, pode ser um indicador de saúde (FRANÇA; PASSO; ROCHA, 2014; WINNICOTT, 2000; 1999b). Ou seja, a saúde é um estado complexo, que precisa ser definido para além da ausência de enfermidade (DIAS, 2003).

Para Winnicott, a saúde é o que leva à descoberta do próprio eu, à importante conquista humana da integração, facilitada pelos cuidados ambientais (FRANÇA; PASSO; ROCHA, 2014; WINNICOTT, 2000). Assim, considera que a saúde dos bebês não pode ser pensada unicamente em termos individuais. Da mesma forma, a conquista da integraçáo pode nunca ocorrer, apesar das boas tendências, uma vez que depende de um ambiente facilitador (WINNICOTT, 2007a; 1990).

Essa concepção de saúde reconhece os cuidados iniciais, como fundamentais para que o bebê comece a existir, ou seja, comece a integrar-se em uma unidade e ao longo do tempo consiga manter essa continuidade de existência. Tais cuidados, altamente especializados e desafiadores, providos por um cuidador suficientemente bom, referem-se àqueles voltados não apenas às necessidades do corpo, mas também relativos à sustentação de sua existência psíquica.

Esses cuidados, que oportunizam uma continuidade de ser através de provisão ambiental suficientemente boa, também são definidos como holding. Ou seja, enquanto a sustentação do indivíduo, que nesse momento, encontra-se em um processo de amadurecimento, partindo da dependência para a independência. Os cuidados cotidianos que envolvem o holding nessa etapa incluem especialmente aqueles relacionados à comunicação não-verbal, considerando o corpo do bebê, integrando espaço e tempo (WINNICOTT, 2007b; DIAS, 2003). No entanto, é importante considerar que nessa etapa o cuidado físico é um cuidado à saúde psíquica (Winnicott, 1990). Assim, reconhece-se a indissociabilidade entre os 
cuidados físicos e psíquicos, de maneira que ambos ocorrem concomitantemente (WINNICOTT, 1999b; DIAS, 2003).

Ao longo de seu amadurecimento, o ser humano passará por uma longa e desafiadora jornada rumo à independência. $\mathrm{O}$ bebê emerge do estado originário de solidão essencial, do não ser, para viver uma experiência de dependência com alguém que possa ajudá-lo a firmar-se no seu existir (WINNICOTT, 2007a). No início, a dependência é absoluta, não havendo ainda uma separação entre eu e não-eu. Não se trata ainda de uma relação a dois, mas de um "dois-em-um” peculiar (CARON; LOPES, 2014). Para esse período, é essencial a presença de um cuidador que se disponha a viver essa dependência junto com o bebê e com ele se identifique de modo a atender às suas necessidades. A dependência passa, assim, a ser mútua, tanto do bebê em relação ao cuidador quanto deste em relação ao bebê.

Em um segundo momento, essa dependência absoluta passa a ser relativa, de modo que há desadaptação ambiental gradativa, oportunizando a abertura de um espaço intermediário ou transicional para a conquista da independência e de uma identidade pessoal. Esse movimento faz parte de um processo de desenvolvimento rumo à integração, cuja principal conquista é uma existência pessoal satisfatória e a possibilidade de viver num mundo de realidade compartilhada, para além do seu mundo subjetivo (WINNICOTT, 2007a).

Cabe ressaltar que o percurso de amadurecimento náo é linear, exigindo por vezes uma regressão à dependência. É nesse constante ir e vir que o ser humano vai se constituindo, no seu processo de amadurecimento pessoal (DIAS, 2003). Cabe lembrar também que os processos que regem a vida psíquica desde o início da vida, e que têm a integração como principal conquista, compóem o núcleo da vida psíquica ao longo do tempo. Assim, esse núcleo se póe em movimento a cada nova experiência, num interminável processo criativo de integração e expansão interna.

Para passar por esses processos iniciais, o bebê conta com algumas disposiçóes inerentes à natureza humana: suas características herdadas e sua tendência inata à integração (WINNICOTT, 2007a; 2005; 1999b). Assim, se o ambiente for suficientemente bom, oferecerá os cuidados necessários para que cresça no seu próprio ritmo, a partir de suas próprias conquistas e criatividade pessoal, constituindo-se, dessa forma, como indivíduo saudável, que sente que a vida vale a pena ser vivida (DIAS, 2003; WINNICOTT, 2007a). No entanto, a ausência de um ambiente facilitador ou a presença de um ambiente intrusivo, que não respeita o gesto 
espontâneo, pode acarretar o encarceramento da disposição inicial ou até mesmo no seu desaparecimento (WINNICOTT, 2007a). Desse modo, as falhas ambientais relativas às experiências iniciais podem ser sentidas pelo bebê como falhas na confiabilidade e continuidade de cuidados, levando a uma interrupção no próprio senso de existir do bebê (WINNICOTT, 2007a). Assim, apesar de a integração ser uma tendência inata de todo ser humano, não é algo que acontece naturalmente. No início, o bebê é um ser não integrado, que necessita de alguém ativamente dedicado e identificado com ele para ajudá-lo, através do corpo e do olhar, a juntar-se, dandolhe a sensação de inteireza, de existência e de coesão psicossomática.

Nesse sentido, destaca-se que a necessidade humana de ser e continuar a ser é o fundamento que acompanhará o indivíduo ao longo da vida (DIAS, 2003; CARON; LOPES, 2014). Para tal, este cuidador precisará regredir a uma condição muito particular, que a permite identificar-se com esse bebê e suas necessidades. Tal condição, que pode durar desde a gestação até algumas semanas após o parto, no caso das mães, Winnicott (2000) chamou de "preocupação materna primária”. A mãe nesse estado fornece um setting para que as tendências do bebê e seus movimentos espontâneos possam se manifestar, no seu longo e interminável processo de desenvolvimento rumo à integração e independência. Ao longo de sua obra, Winnicott também descreveu algumas qualidades dessas mães que são capazes de adaptar-se às necessidades de seu bebê: ser real, empática, devotada, monótona, suficiente, constante, previsível e preocupada (CARON; LOPES, 2014).

Assim, os cuidados iniciais proporcionam ao bebê as condições necessárias para iniciar seu processo de conquista da integração, para que ele gradualmente possa reconhecer também a existência de um outro nessa relação, e desenvolver a capacidade para concernimento, inerente à relação entre duas pessoas separadas (WINNICOTT, 2007a). Um dos desdobramentos de ter recebido cuidados suficientemente bons é a capacidade de desenvolver uma identificação com seus cuidadores, ou seja, cuidar de si e de outros. Dessa forma, posteriormente, a criança também será capaz de cuidar do próprio ambiente, responsabilizando-se por suas açóes. Em outras palavras, isso implica no desenvolvimento da capacidade de adaptar-se ao mundo e à coletividade sem a perda de sua condição individual, de um si mesmo, sem sacrifício da própria espontaneidade (WINNICOTT, 2005; FULGENCIO, 2011).

Ao longo de sua obra, Winnicott também nos mostra que as mães cuidam de seus bebês através dos tempos, independentemente de uma compreensão intelectual 
sobre esse processo. Da mesma forma, os bebês desenvolvem-se independentemente de nossa compreensão, embora, como profissionais, compreender o amadurecimento possa ser uma forma de fundamentar práticas voltadas ao cuidado desses bebês (WINNICOTT, 2007a). Assim, refletir sobre o estreito vínculo entre saúde e desenvolvimento, brevemente considerado, faz-se extremamente pertinente para se pensar o campo da saúde pública voltada aos bebês, sobretudo ao pensarmos os efeitos de ser cuidado. Essa articulação salienta a importância de levar em consideração o ambiente em que o bebê se desenvolve, em particular, as especificidades da relação mãe-bebê para o desenvolvimento de sua saúde integral.

\section{Um diálogo entre a teoria de desenvolvimento emocional de Winnicott e a Rede Cegonha}

Tendo em vista a possibilidade de diálogo entre algumas formulações de Winnicott e a portaria que institui a Rede Cegonha (BRASIL, 2011), apresenta-se a seguir, uma síntese crítica que se propóe a contribuir teoricamente para a atenção à saúde materno-infantil com uma discussão acerca das especificidades do desenvolvimento do bebê nesse período. Para fins de exposição, organiza-se a análise crítica em torno dos seguintes eixos norteadores: Características integradoras do cuidado; Cuidar do cuidador; Singularidade do cuidado; e Ética do cuidado. O material usado para essa discussão envolve elementos da teoria de Winnicott, descritos anteriormente, e a Portaria 1.459 que estabelece a Rede Cegonha (BRASIL, 2011). Para essa articulação, é dada especial atenção aos objetivos, princípios, diretrizes e componentes dessa portaria.

\section{Características integradoras do cuidado}

Um primeiro ponto a ser destacado é que a Rede Cegonha está atenta, em seus objetivos, tanto à mãe no período de gravidez, parto e puerpério, como ao bebê, desde a gestação até os seus dois anos de vida. Entendemos que tal proposição favorece uma atuação integradora dos profissionais de saúde, uma vez que reconhece essa indissociabilidade inicial.

Sobre a estrutura da Rede Cegonha, mais especificamente, ressaltam-se também nos princípios norteadores algumas características que podem ser consideradas como promotoras do processo de integração do bebê e da mãe, tais como a continuidade 
e a previsibilidade do cuidado (WINNICOTT, 2007a; SERRALHA, 2013). Em ações previstas, também estáo estabelecidos procedimentos facilitadores de tais características, como o acolhimento inicial, a vinculação da gestante ao local de parto, o acompanhamento da puérpera e do bebê após o nascimento, a garantia ao deslocamento em situaçôes necessárias, além da qualificação do sistema de informaçôes.

Observa-se que, apesar de os objetivos da Rede Cegonha abrangerem a saúde materno-infantil da gestação até os 24 meses de vida do bebê, a portaria não inclui em seus componentes uma descrição dos cuidados à dupla mãe-bebê na etapa que ocorre após o puerpério. Assim, ressalta-se a importância de descrever quais cuidados serão oferecidos, e como eles serão organizados, no sentido de reiterar esse direito, visto que tal atenção já está prevista pelos objetivos da Rede Cegonha e viria a ressaltar a sua característica integradora do cuidado à saúde.

Para o bebê, a continuidade de cuidados é muito importante, desde o período de dependência absoluta, que vai da gestação até por volta dos cinco meses de vida, seguindo no período de dependência relativa (dos seis aos 24 meses de vida). A adaptação contínua e confiável do ambiente às necessidades do bebê ao longo desse período é fundamental para que o mesmo possa firmar-se em sua existência, e posteriormente dar continuidade à sua jornada de amadurecimento emocional rumo à integração e independência (WINNICOTT, 2007a). Assim, torna-se indispensável contemplar a explicitação das ações de atenção à saúde materno-infantil para além da gestação e parto, abarcando todo período relativo aos dois primeiros anos de vida.

Ainda, apesar de sua proposição integradora, descrita anteriormente, percebe-se que durante sua implementação, serviços da Rede Cegonha ainda permaneciam fragmentados, de forma que o objetivo de integração do cuidado náo havia sido alcançado (FERNANDES; VILELA, 2014). Ainda, observa-se que atualmente algumas práticas continuam sendo um desafio. Por exemplo, no estudo de Andrade e Rodrigues (2017), identificou que das 337 mães, apenas 51,6\% tiveram contato pelea-pele com seu bebê logo após o parto, e menos da metade realizou a amamentação na sala de parto. É importante estar atentos a esses dados, considerando que o que está em jogo nesse processo é justamente a conquista da integraçáo enquanto coesão psicossomática (WINNICOTT, 2007a; 1990).

Os pontos destacados acima sugerem que a Rede Cegonha acaba enfrentando algumas dificuldades para sua implementaçáo, no que diz respeito ao cuidado integrado, conforme descrito em sua portaria. Essas dificuldades podem estar 
associadas a diversos aspectos que dificultam sua implementação, entre eles a extensão do território brasileiro e do quanto pode ser complexo executar os objetivos propostos na portaria. De qualquer modo, reconhece-se a importância e potencial dessa política para a atenção à saúde materno-infantil, contemplando, ao menos em parte, um novo paradigma de saúde, desenvolvimento e cuidado na primeira infância do bebê.

\section{Cuidar do cuidador}

Como abordado anteriormente, na etapa mais primitiva do amadurecimento emocional, o bebê necessita dos cuidados a mbientais que facilitem o desenvolvimento de tendências inatas do bebê rumo à integração (WINNICOTT, 2007a; 1994). No entanto, considerando que a mãe está sendo intensamente demandada nesse processo e que pode ficar fragilizada por conta disso, torna-se importante estabelecer uma rede de cuidados para ela própria. Nesse sentido, a Rede Cegonha se faz relevante visto que a "rede" pode atuar como um importante dispositivo de sustentação para a relação mãe-bebê. Assim, entende-se que o holding ofertado por essa rede favorece o cuidador também em sua função de sustentar a existência de seu bebê.

Destacamos a importância de envolver os próprios familiares para que a Rede Cegonha possa funcionar como sustentação. Essa função de cuidado por parte de outros familiares se torna importante, sobretudo nesse período inicial, por representar uma sustentação para a mãe, que, como diz Winnicott (1990), pode estar tão desamparada quanto o próprio bebê. Assim, reconhecendo as potencialidades dos cuidados que outros membros da família podem despender à dupla mãe-bebê, é possível pensar na inserção e na ampliação de familiares na rede de cuidados à saúde materno-infantil proposta pela Rede Cegonha.

Contudo, apesar de tais prerrogativas serem asseguradas pela Rede Cegonha, a literatura tem indicado problemas na operacionalização dos cuidados. Estudo (GOTTEMS et al., 2015) com 30 usuárias da Rede Cegonha do Distrito Federal, identificou, através dos relatos, uma discrepância entre o que estava previsto nos princípios norteadores da Rede Cegonha e a atenção que efetivamente recebiam. Outros problemas relatados abrangiam desde pouca procura da vinculação com a maternidade até situaçóes de violência institucional, como práticas obstétricas não recomendadas e que geravam risco para a parturiente.

Nessa direção, é necessário salientar também a discussão sobre a complexidade envolvida na mudança de práticas instituídas há tantos anos, e que têm em seu bojo 
aspectos históricos, sociais e culturais envolvidos. A prática de saúde fragmentada e despersonalizada, que diversos programas e políticas, tais como a Rede Cegonha, visam modificar, ainda parece estar em vigor. Portanto, é necessário seguir pensando em açóes que, para além de se estabelecerem como direito, insiram o cuidado ao cuidador do bebê como uma prática alinhada à humanização da atenção à saúde, e presente no cotidiano dos profissionais de saúde na atenção à saúde do bebê.

\section{Especificidades do cuidado à saúde materno-infantil}

A Rede Cegonha reconhece também as necessidades distintas a serem atendidas em diferentes momentos da dupla mãe-bebê. Como exemplo, é notável a especial atenção dedicada à primeira semana de vida da criança, quando está prevista na portaria uma visita domiciliar ao bebê e sua mãe (BRASIL, 2011). A especificidade do serviço de saúde nessa fase revela uma disponibilidade de atenção muito particular, considerando a demanda singular que este período exige.

Reconhecer a especificidade da atenção à saúde materno-infantil nesse período também é reconhecer que promover saúde é oferecer condiçôes facilitadoras ao crescimento e ao amadurecimento do indivíduo (WINNICOTT, 2005; FULGENCIO, 2011). Do mesmo modo, a Rede Cegonha parece ter uma preocupação a respeito das diferentes formas de existir da mãe e do bebê, destacando em seus princípios o respeito às diferentes culturas e modos de ser dos usuários, reafirmando, assim, alguns valores já estabelecidos no SUS, que também passou por inúmeros avanços e reformulaçôes ao longo de seu percurso (PERREAULT et al.,2016).

A respeito dos princípios de acesso e viabilização de uma adequada atenção à saúde, cabe destacar a forma de organização dessa atenção em outros países que, embora muito diferentes do Brasil, podem elucidar alternativas para lidar com a questáo da diversidade. Por exemplo, países como a Austrália e a Inglaterra também têm sistemas de saúde de acesso universal, semelhantes ao SUS. No que tange ao planejamento de atenção à saúde materno-infantil, observam-se algumas semelhanças entre a Rede Cegonha e o que é proposto pelos sistemas Medicare, da Austrália, e National Health Service, da Inglaterra. Essas semelhanças podem ser vistas na preocupação com a continuidade do cuidado, com a vinculação da mulher ao local do parto, além de priorizar as especificidades de cuidado de cada indivíduo e a relação profissional-usuário. 
Sobre os aspectos práticos do dia a dia da Rede Cegonha, Carneiro (2013) assinala que essa rede reconhece as necessidades da mulher, e respeita os seus direitos e os do bebê. Contudo, o programa pode suscitar questionamentos sobre a diversidade da atenção prestada. A autora alerta que as mulheres podem não desejar o mesmo cuidado previsto em Lei, pois esse cuidado não necessariamente contempla a singularidade de cada dupla mãe-bebê. Além disso, como citado anteriormente, diversos aspectos relacionados ao cuidado previsto na portaria da Rede Cegonha podem não estar sendo cumpridos nas açôes. Cabe ainda destacar que aspectos relacionados à diversidade cultural, desigualdade social e os avanços em relação às questôes de gênero merecem destaque e atenção às suas especificidades.

No tocante especificamente ao desenvolvimento do bebê, obviamente não existem garantias que assegurem esse processo por força de uma Lei. A principal necessidade do bebê é ser e continuar a ser, a partir de experiências de cuidado contínuo e previsível que, em longo prazo, facilitam o desenvolvimento de um modo pessoal de existir no mundo (WINNICOTT, 2007a; 2005; 1999b). Contudo, propomos que compreender a saúde pela perspectiva da garantia de direitos é o primeiro passo para alcançar as condiçôes necessárias ao respeito à singularidade de cada dupla mãe-bebê. Winnicott pode nos ajudar a compreender toda essa especificidade de um cuidado com potencialidades para a promoção de saúde integral, nas diferentes açôes de um serviço ou de uma rede de atenção à saúde materno-infantil, fundamentada em uma ética do cuidado.

\section{Ética do cuidado}

$\mathrm{Na}$ área da saúde, cabe ressaltar a implicação do profissional em proporcionar as condições necessárias e o reconhecimento das necessidades de cuidados em particular, que, no caso da Rede Cegonha, se trata da díade mãe-bebê. Esse reconhecimento implica, também, levar em consideração a singularidade de cada dupla mãe-bebê, própria de uma ética singular (SERRALHA, 2013). Loparic (2013) formaliza a ideia de que a proposição de cuidado de Winnicott, no sentido ético, define-se como um novo paradigma, fundamentado na necessidade constitutiva da natureza humana de receber cuidados do ambiente. Essa ética do cuidado implica na aceitação da responsabilidade pela existência e sustentação de um novo ser humano.

Assim, o cuidador que se responsabiliza pela sustentação de um novo ser transmite o "poder ser" para o bebê, a partir de sua tendência inata à integração. 
Ou seja, facilita o desenvolvimento e o amadurecimento do bebê a partir do que potencialmente ele já é. Sendo assim, esse cuidado inaugura, não uma forma de agir, mas uma ética de ser enquanto um traço inerente ao ser humano (LOPARIC, 2013). De modo análogo, propomos fundamentar uma atenção à saúde materno-infantil em uma ética do cuidado, o que significa realizar as práticas de saúde levando em consideração a facilitação do vir-a-ser do bebê, enquanto um percurso rumo à integração. Muitas vezes, uma forma de oferecer esse espaço é acolher e escutar as mães e seus bebês, em suas singularidades, a partir de uma postura não julgadora, receptiva e continente (CARON; LOPES, 2014).

Assim, enquanto o cuidador oportuniza uma sustentação, possibilitando ao bebê a sua existência enquanto indivíduo (LOPARIC, 2013), o profissional de saúde pode operar de um posicionamento ético voltado para o cuidado a partir de uma rede que sustente também o cuidador (SERRALHA, 2013). Diante disso, entende-se que quando a Rede Cegonha se propõe a sustentar a relação mãe-bebê, oportunizando espaços de saúde e açóes contínuas de cuidado, está proporcionando não apenas o cuidado técnico, que é extremamente necessário, mas também um cuidado para com a existência de um novo ser em constituição.

Por fim, entendemos que esse diálogo entre a Rede Cegonha e a teoria do amadurecimento pode trazer algumas contribuições para o campo da saúde coletiva, uma vez que a saúde social depende da saúde individual de seus membros (WINNICOTT, 1999b). Como brevemente apresentado em seçâo anterior, a sustentação (holding) envolvida nos cuidados iniciais de um bebê, que facilitam o seu processo de amadurecimento, também estão na origem da capacidade de concernimento e senso ético do indivíduo. Sendo assim, é importante considerar que existem impactos sociais envolvidos no cuidado à saúde da mãe e de seu bebê, que facilitam não somente o amadurecimento individual, mas social (GARCIA, 2011). Além disso, o cuidado dispensado nos primeiros anos para com os membros de uma sociedade também repercute no desenvolvimento da mesma, pois é através dele que indivíduos maduros podem, inclusive, contribuir para a manutenção de sua democracia (WINNICOTT, 1999c).

\section{Considerações finais}

Por meio deste artigo, buscou-se uma análise crítica da Rede Cegonha, com especial atenção aos seus objetivos, princípios, diretrizes e componentes, a partir de 
um diálogo com a teoria do desenvolvimento emocional de Winnicott. Alguns dos elementos teóricos apresentados e discutidos, referentes aos processos característicos da díade mãe-bebê e processo de integração do bebê, foram abordados e articulados com a portaria. Essa discussão é apresentada a partir de quatro eixos norteadores: Características integradoras do cuidado; Cuidar do cuidador; Especificidades do cuidado; e Ética do cuidado. Também foram referidos estudos que examinaram o funcionamento da Rede Cegonha, apontando particularidades e desafios ainda enfrentados pela proposta.

Assim, através deste estudo, foi possível refletir sobre os princípios norteadores da Rede Cegonha, suas implicaçóes para a saúde do bebê, e até mesmo apontar estratégias que ajudem a garantir que esses princípios se mantenham nas açóes a partir de uma ética do cuidado. Salientamos, também, a importância de fomentar uma discussão que ultrapasse o que é ou não realizado nos serviços e práticas de saúde, tendo em vista que a portaria que estabeleceu a Rede Cegonha não tem a propriedade de garantir a forma como esse cuidado é operacionalizado pelos profissionais. Assim, acreditamos ter reiterado o potencial dessa política para uma efetiva atenção à saúde do bebê, pautada pela responsabilidade por um ser em constituição que efetivamente considere a singularidade de cada dupla mãe-bebê. ${ }^{1}$

\section{Referências}

ANDRADE, L. F. B.; RODRIGUES, Q. P.; SILVA, R. C. V. Boas práticas na atenção obstétrica e sua interface com a humanização da assistência. RevEnferm UERJ, v. 25, n. 1, n.p., 2017. Disponível em: <https://doi.org/10.12957/reuerj.2017.26442>.

BRASIL. Politica Nacional de Atenção Integral à Saúde da Criança: orientaçóes para implementação, 2018. Disponível em: <http://www.saude.pr.gov.br/arquivos/File/Politica_ Nacional_de_Atencao_Integral_a_Saude_da_Crianca_PNAISC.pdf $>$.

. Portaria no 1.130, de 5 de agosto de 2015. Institui a Política Nacional de Atenção Integral à Saúde da Criança (PNAISC) no âmbito do Sistema Único de Saúde (SUS). Diário Oficial da União, Brasília-DF, 5 ago. 2015. Disponível em: <http://bvsms.saude.gov.br/bvs/ saudelegis/gm/2015/prt1130_05_08_2015.html>.

- Implantação das Redes de Atenção à Saúde e outras estratégias da SAS. Brasília: Editora MS, 2014. Disponível em: <http://bvsms.saude.gov.br/bvs/publicacoes/implantacao_redes_ atencao_saude_sas.pdf $>$. 
. Portaria $n^{\circ} 1.459$, de 24 de junho de 2011. Institui no âmbito do Sistema Único de Saúde - SUS - a Rede Cegonha. Diário Oficial da Uniāo, Brasília-DF, 24 dez. 2011. Disponível em: <http://bvsms.saude.gov.br/bvs/saudelegis/gm/2011/prt1459_24_06_2011.html>.

. Portaria no 4.279, de 30 de dezembro de 2010. Estabelece diretrizes para a organização da Rede de Atenção à Saúde no âmbito do Sistema Único de Saúde (SUS). Diário Oficial da União, Brasília-DF, Seção 1, p. 89, 31 dez. 2010. Disponível em: <http://bvsms.saude.gov.br/ bvs/saudelegis/gm/2010/prt4279_30_12_2010.html>.

Portaria no 2.395, de 7 de outubro de 2009. Institui a Estratégia Brasileirinhas e Brasileirinhos Saudáveis e cria o Comitê Técnico-Consultivo para sua implementação. Diário Oficial da União, Brasília-DF, 07 de out. 2009. Disponível em: <http://bvsms.saude.gov.br/bvs/ saudelegis/gm/2009/prt2395_07_10_2009.html>.

. Portaria no 569, de $1^{\circ}$ de junho de 2000. Diário Oficial da União, Brasília-DF, no 110, Seção 1, p. 4, 6 jun. 2000. Disponível em: <http://bvsms.saude.gov.br/bvs/saudelegis/gm/2000/ prt0569_01_06_2000_rep.html>.

Lei no 8.800, de 19 de setembro de 1990. Dispóe sobre as condiçóes para a promoção, proteção e recuperação da saúde, a organização e o funcionamento dos serviços correspondentes e dá outras providências. Diário Oficial da República Federativa do Brasil, Poder Executivo, Brasília, DF, 19 set. 1990. Disponível em: <http://www.planalto.gov.br/ccivil_03/leis/18080.htm>.

. Assistência Integral à Saúde da Mulher: Bases de ação programática. Brasília: Centro de documentação do Ministério da Saúde, 1984. Disponível em: <http://bvsms.saude.gov.br/bvs/ publicacoes/assistencia_integral_saude_acao_programatica.pdf>

CARNEIRO, R. G. Dilemas antropológicos de uma agenda de saúde pública: Programa Rede Cegonha, pessoalidade e pluralidade. Interface-Comunicação, Saúde, Educação, v. 17, p. 49-59, 2013. Disponível em: <http://dx.doi.org/10.1590/S1414-32832013000100005>.

CARON, N. A.; LOPES, R. C. S. Aprendendo com as mães e os bebês sobre a natureza humana e a técnica analítica. Porto Alegre: Dublinense, 2014.

CASSIANO, A. C. M. et al. Saúde materno infantil no Brasil: evolução e programas desenvolvidos pelo Ministério da Saúde. Revista do Serviço Público, v. 65, n. 2, p. 227-244, 2014. Disponível em: <https://doi.org/10.21874/rsp.v65i2.581>.

DI GIOVANNI, M. Rede Cegonha: da concepção à implantação. Brasília: Escola nacional de Administração Pública, 2013.

DIAS, E. O. A teoria do amadurecimento de D. W. Winnicott. Rio de Janeiro: Imago, 2003.

FERNANDES, R. Z. S.; VILELA, M. F. D. G. Estratégias de integração das práticas assistenciais de saúde e de vigilância sanitária no contexto de implementação da Rede Cegonha. Ciência \& Saúde Coletiva, v. 19, p. 4457-4466, 2014. Disponível em: <http://dx.doi.org/10.1590/1413812320141911.21662013>. 
FRANÇA, R. M. P.; PASSOS, M. C.; ROCHA, Z. Os sentidos da saúde na obra de Donald Winnicott. Estudos de Psicanálise, v. 42, p. 97-106, 2014. Disponível em: <http://pepsic.bvsalud. org/scielo.php?script=sci_arttext\&pid=S0100-34372014000200011\&lng=pt\&nrm=iso >.

FULGENCIO, L. A ética do cuidado psicanalítico para D. W. Winnicott. A peste: Revista de Psicanálise e Sociedade e Filosofia, v. 3, n. 2, p. 39-62, 2011. Disponível em: <https://doi. org/10.5546/peste.v3i2.22088>.

GARCIA, R. M. A ética do cuidado e a sociedade democrática. Winnicotte-prints, v. 6, n. 1, p. 7987, 2011, Disponível em: <http://pepsic.bvsalud.org/scielo.php?script=sci_arttext\&pid=S1679432X2011000100006>.

GIOVANELLA, L. et al. Sistema universal de saúde e cobertura universal: desvendando pressupostos e estratégias. Ciênc. Saúde Coletiva, Rio de Janeiro, v. 23, n. 6, p. 1763-1776, 2018. Disponível em: <http://dx.doi.org/10.1590/1413-81232018236.05562018>.

GOTTEMS, L. B. D. et al. Acesso à rede de atenção à gestação, parto e nascimento na perspectiva das usuárias. Revista Eletrônica Gestão \& Saúde, v. 6, n. 1, p. 95-115, 2015. Disponível em: <http://periodicos.unb.br/index.php/rgs/article/view/2531/2258>.

LOPARIC, Z. A ética da Lei e a ética do cuidado. In: . (Org.). Winnicott e a ética do cuidado. São Paulo: DWW Editorial, 2013. p. 19-52.

MARQUES, C. P. C. Redes de atenção à saúde: a Rede Cegonha. EDUFMA: São Luís, 2016.

MENDES, E. V. 25 anos do Sistema Único de Saúde: resultados e desafios. Estudos Avançados, v. 27, n. 78, p. 27-34, 2013. Disponível em: <http://dx.doi.org/10.1590/S010340142013000200003>.

PASCHE, D. F. et al. Rede Cegonha: desafios de mudanças culturais nas práticas obstétricas e neonatais. Divulgação em Saúde para Debate, v. 52, p. 58-71, 2014.

PENELLO, L. M. et al. Estratégia Brasileirinhas e Brasileirinhos Saudáveis: Primeiros Passos para o Desenvolvimento Nacional. Trivium - Estudos Interdisciplinares, v. 3, n. 2, p. 106-113, 2011. Disponível em: <http://bvsms.saude.gov.br/bvs/palestras/humanizacao/brasileirinhos_ apresentacao_dra_liliane.pdf $>$.

PERREAULT, M. et al. Programa de saúde da família no Brasil: Reflexôes críticas à luz da promoção de saúde. Revista Enfermagem Contemporânea, v. 5, n.1, p. 159-179, 2016. doi: 10.17267/2317-3378rec.v5i1.897. Disponível em: <https://www5.bahiana.edu.br/index.php/ enfermagem/article/download/897/660>.

PITOMBO, L. B.; MAIA, M. S.; ROSARIO, S. E. do. Estratégia Brasileirinhas e Brasileirinhos Saudáveis (EBBS): formando e transformando no campo da saúde pública. Trivium - Estudos Interdisciplinares, v. 6, n. 2, p. 109-116, 2014. Disponível em: <http://pepsic.bvsalud.org/scielo. php?script=sci_arttext\&pid=S2176-48912014000200011\&lng=pt\&nrm=iso $>$. 
SERRALHA, C. A. A ética do cuidado e as açôes em saúde e educação. In: LOPARIC, Z. (Org.). Winnicott e a ética do cuidado. São Paulo: DWW Editorial, 2013. p.319-336.

SERRUYA, S. J.; CECATTI, J. G.; LAGO, T. G. O Programa de Humanização no Pré-natal e Nascimento do Ministério da Saúde no Brasil: resultados iniciais. Cadernos de Saúde Pública, v. 20, p. 1281-1289, 2004.

SILVA, J. L. P. E.; CECATTI, J. G.; SERRUYA, S. J. A qualidade do pré-natal no Brasil. Revista Brasileira de Ginecologia e Obstetricia, v. 27, n. 3, p. 103-105, 2005. Disponível em: <https://dx.doi.org/10.1590/S0100-72032005000300001>. Acesso em: 03 jul. 2019

VICTORA, C. Evidências científicas sobre a importância da primeira infância: a estratégia dos 1000 dias. Avanços do Marco Legal da Primeira Infância. Brasília: Centro de Estudos e Debates Estratégicos, 2016.

WINNICOTT, D. W. O ambiente e os processos de maturação. Porto Alegre: Artmed, 2007a. . Teoria do relacionamento paterno-infantil. In: . O ambiente e os processos de maturação. Porto Alegre: Artmed, 2007b. p. 38-54.

. A familia e o desenvolvimento individual. São Paulo: Martins Fontes, 2005. . Da pediatria à psicanálise. Rio de Janeiro: Imago, 2000.

. Desenvolvimento emocional primitivo. In: . Da pediatria à psicanálise: obras escolhidas. Rio de Janeiro: Imago, 2000, p. 218-232.

. A amamentação como forma de comunicação. In: . Os bebês e suas mães. São Paulo: Martins Fontes, 1999a, p. 19-28.

O conceito de indivíduo saudável. In: - Tudo começa em casa. São Paulo: Martins Fontes, 1999b. p. 3-22.

. Algumas reflexóes sobre o significado da palavra "democracia". In: Tudo começa em casa. São Paulo: Martins Fontes, 1999c, p. 249-272.

. D. W. W sobre D. W. W. Explorações Psicanalíticas. Porto Alegre: Artes Médicas, 1994. p. 433-444.

Integração. In: . Natureza humana. Rio de Janeiro: Imago, 1990, p. 136-142. . A criança em marcha. In: . A criança e seu mundo. Rio de Janeiro: Zahar Editores, 1979, p. 26-30.

\section{Nota}

${ }^{1}$ G. C. Esswein e L. P. de Teixeira: concepção do trabalho, análise crítica, revisão da literatura, escrita e revisão final do artigo. R. C. S. Lopes e C. A. Piccinini: concepção do trabalho, análise crítica da discussão e revisão final do artigo. 


\section{Abstract}

\section{Baby's healthcare in Rede Cegonha: a dialogue with Winnicott's theory on the specificities of emotional development}

In 2011, the Ministry of Health established the Rede Cegonha ("Stork Network"), to ensure full and integrated care, from pregnancy to 24 months of life. On this important advance, this article aims to promote a critical analysis of the Stork Network Ordinance from a dialogue with Winnicott's theory of personal maturity. The results of our analysis are presented from four guiding axes: Integrative characteristics of care, in which we discuss characteristics of the Rede Cegonha that favor an integrative care; Caring for the caregiver, in which we emphasize the possibilities of this network to support of the double mother-baby; Specificities of maternal and child health care, in which we discuss the attention to the specifics of the initial emotional development process; and Ethics of care, in which we highlight the need for an ethical posture implied in the care. This article indicated the potentialities and weaknesses of the Rede Cegonha, bringing new perspectives to improve maternal and child health care especially in the first two years of life. Finally, we emphasize that although policy does not guarantee the way how care is operationalized, we reiterate the Rede Cegonhas's potential for an integrator maternal and child health care.

Keywords: maternal-child healthcare; Unified Health System; Psychoanalysis; child development. 